
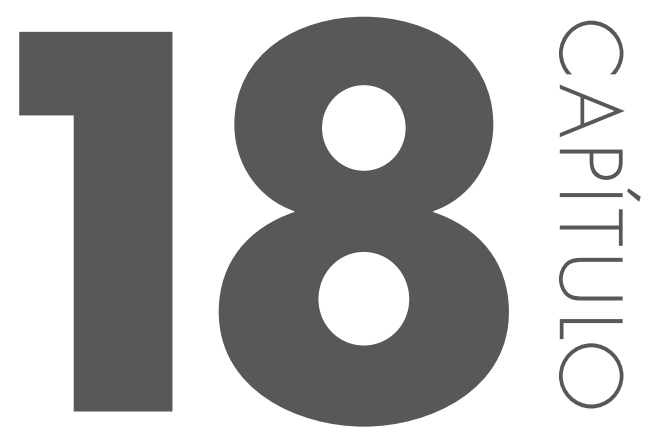

\title{
POLÍTICAS HABITACIONAIS NO BRASIL: AS MORADIAS POPULARES E A FORMAC̣ÃO SOCIOESPACIAL URBANA
}

Nunes, Luciana Meira dos Santos ${ }^{1 *}$; Mendes, Estevane de Paula Pontes ${ }^{2}$

1 Mestranda do Programa de Pós-Graduação em Geografia. Universidade Federal de Goiás - Regional Catalão

2 Prof. ${ }^{a}$ Dra. do Programa de Pós-Graduação em Geografia. Universidade Federal de Goiás - Regional Catalão

* email: lucianameira1@hotmail.com

\section{RESUMO}

As questões referentes à moradia são essenciais no debate sobre a transformação do espaço urbano brasileiro. A demanda habitacional das classes sociais menosfavorecidas economicamentemovimenta ações políticas e aquece o mercado imobiliário associado aos programas habitacionais. O objetivo específico deste trabalho é analisar o desenvolvimento das políticas habitacionais como formas de promover a transformação do espaço e concomitantemente perpetuar a segregação social e residencial nas cidades, especificamente na Região Administrativa de São Sebastião no Distrito Federal. Justifica-se esse debate para compreender os mecanismos 
criados por meio dos programas habitacionais para distinguir as pessoas que podem adquirir um imóvel em um lugar que ofereça infraestrutura básica e assim ter garantido seu direito à moradia digna, preconizado pelo Estatuto da Cidade, em diferentes localidades do espaço urbano. A organização do território de uma cidade depende de estudos e de políticas que tenham por finalidade proteger o meio ambiente e oferecer qualidade de vida para população residente. Tarefa árdua para uma população humana que está em constante crescimento. Contudo, além da necessidade de planejar, há outra questão se faz presente no ordenamento territorial: a vontade política. Pode-se dizer que ordenar o território envolve ações teóricas e práticas. Com isso tem-se por um lado os estudos, pareceres técnicos, relatórios e documentos que organizam uma certa região, configurando a parte teórica. Por outro lado, há os interesses políticos, os interesses capitalistas, as necessidades da população, enfim, essa é a parte prática.

Palavras-chave: moradia; políticas habitacionais; Distrito Federal

Nunes, Luciana Meira dos Santos; Mendes, Estevane de Paula Pontes; "POLÍTICAS HABITACIONAIS NO BRASIL: AS MORADIAS POPULARES E A FORMAÇÃO SOCIOESPACIAL URBANA", p. 288-305 . In: Seminário de Pesquisa, PósGraduação e Inovação da Regional Catalão (2. : 2014 : Goiás) Coletânea Interdisciplinar em Pesquisa, PósGraduação e Inovação - Volume 1 : Estudos Ambientais, Território e Movimentos Sociais. Anais [livro eletrônico] / organizado por Adriana Freitas Neves, Idelvone Mendes Ferreira, Maria Helena de Paula, Petrus Henrique Ribeiro dos Anjos. São Paulo: Blucher, 2015. ISBN: 978-85-8039-109-1, DOI 10.5151/9788580391091-V1_Cap18 


\section{A QUESTÃO DA MORADIA E UM BREVE HISTÓRICO DAS POLÍTICAS HABITACIONAIS NO BRASIL}

As questões que envolvem a complexidade do direito à moradia requerem a compreensão sobre os aspectos geográficos como demografia, crescimento urbano, planejamento, política públicas e economia. Todas essas questões estão interligadas no processo de construção, venda e habitação da população brasileira. Sobre a transformação do espaço, a sociedade humana vive o ápice da produção habitacional no Brasil, produção essa destinada para todas classes sociais, as quais estão em processo de ascensão social ocasionadas dentre outros fatores, pelo próprio crescimento urbano. A produção habitacional possui um histórico de avanços e retrocessos na política brasileira, conforme será apresentado.

Para Borges (2013), a entrada do Estado Brasileiro nas questões referentes à habitação ocorreu no final do século XIX, a partir de um ponto de vista eminentemente sanitarista. Com o intuito de enfrentar a propagação de doenças e epidemias nas grandes cidades, que se adensavam fortemente. Assim, segundo Bonduki (1998), uma das principais vertentes de ação do Estado foi justamente a promoção da atuação de médicos nos interiores das casas da população humana de baixa renda, em especial nas regiões centrais do País. Essa ação tinha como objetivo promover o controle sanitário das habitações. Paralelamente a esta ação, ocorrem iniciativas regulatória.

Exemplo dessas iniciativas, de acordo com Bonduki (1998), são os Códigos Sanitários e os de Posturas, que entre outras definições de padrões, tratam do estabelecimento de parâmetros para a construção de moradias operárias. Por décadas, como aponta Borges (2013), não existiu nessas abordagens qualquer ação de promoção de habitação, e sim a abordagem da habitação popular como espaço patológico, a ser tratado do ponto de vista da salubridade. A ideia de "beneficiários" da política de habitação evidentemente não existiu sob esse ponto de vista, segundo Bonduki:

A questão da provisão habitacional é colocada pela primeira vez durante a ditadura Vargas, quando Estado e setores técnicos passam a discutir a superação das condições precárias de moradia de aluguel, tendo como pressuposto a conquista da casa própria. Com raras exceções favoráveis a mecanismos que tratam a provisão de moradia pelo Estado como um serviço público, como a construção de habitações de aluguel, a posição adotada por técnicos e pelo 
Estado foi pela produção de moradia popular como casa própria. (BONDUKI, 1998, p. 45).

De acordo com o histórico da política habitacional, elaborado pela Caixa Econômica Federal (2011), a primeira iniciativa brasileira de criação de uma política habitacional de abrangência nacional, com objetivos e metas definidos, fontes de recursos permanentes e mecanismos próprios de financiamento ocorreu em 1964, com a edição da Lei $n^{\circ}$ 4.380/1964. Esta Lei instituiu o Sistema Financeiro de Habitação (SFH), o Banco Nacional da Habitação (BNH) e a correção monetária nos Contratos Imobiliários de Interesse Social. A partir de então, o Governo Federal passou a ter as atribuições de formular a Política Nacional de Habitação e coordenar as ações públicas e privadas para estimular a construção e o financiamento para aquisição de habitações de interesse social.

A política habitacional executada pelo $\mathrm{BNH}$ teve por objetivo viabilizar o acesso à moradia aos diferentes estratos sociais, com foco nas famílias de baixa renda. Foi financiada com recursos do SFH provenientes do Sistema Brasileiro de Poupança e Empréstimo (SBPE) e do Fundo de Garantia por Tempo de Serviço (FGTS). Ainda, de acordo com a Caixa Econômica Federal (CEF, 2012), a crise econômica no final dos anos 1970 provocou aumento da inflação, desemprego, queda dos níveis salariais, o que gerou um forte desequilíbrio no SFH em decorrência das seguidas alterações nas regras de correção monetária. Tal cenário resultou na extinção do BNH, pelo Decreto - Lei 2.291/86, de novembro de 1986, cujas funções foram redistribuídas por vários órgãos do governo.

Coube a Caixa Econômica Federal (CEF) a administração do passivo, do ativo, do pessoal e dos bens do BNH, bem como a operação do FGTS, assumindo, desde então a condição de maior executor das políticas habitacionais do Governo Federal. Neste contexto há na atualidade o desenvolvimento do programa habitacional "Minha Casa, Minha Vida”, o qual terá suas diretrizes analisadas a seguir.

Para Moreira (2013), o Governo que iniciou-se em 2003 representa um marco na Política Urbana Brasileira. Realmente é visível o aumento das construções de habitações em vários municípios brasileiros. Observa-se no Distrito Federal, especificamente, as obras de prédios destinados à moradia tanto pelas Empresas privadas como obras associadas com as políticas habitacionais. A construção civil está tendo um crescimento elevado, principalmente devido as construções de habitações. O crescimento populacional e o processo de urbanização em si têm promovido a expansão desse setor. Sobre esse fato, Moreira (2013), aponta: 
A reorganização da estrutura institucional gestora dessa política, a alteração no foco de atendimento e o significativo aumento dos recursos caracterizam, principalmente, o período do governo Lula, o que se estende ao início do Governo Dilma. Ainda que se tenha avançado pouco em problemas centrais da política urbana, como a questão fundiária, a política habitacional viabilizou a produção de moradias em volume expressivo, principalmente se consideramos as décadas anteriores de baixíssimo investimento nessa área. (MOREIRA, 2013, p.21-22).

É notório que a moradia tem tido papel de destaque nas políticas públicas, e que tem sido um dos problemas urbanos que mais receberam investimentos por parte dos Governos nas esferas Federal, Estadual e Municipal. Vale destacar que o fato de todas pessoas necessitarem de moradia, faz de cada família um demandante em potencial no mercado de habitação, isso também justifica o crescimento do mercado imobiliário na atualidade. Como Moreira (2013) descreve, independentemente do nível de renda, todos precisam de moradia e o alto preço da habitação torna sua comercialização dependente de esquemas de financiamento de longo prazo.

A durabilidade elevada desse bem faz com que políticas habitacionais antigas influenciem no atual estado do mercado. Logo, o atual estágio das políticas voltadas para a construção de moradias é fruto de políticas antigas que não atendiam ao crescimento populacional e a expansão da cidade como um todo. A seguir são apontados fatores interligados com a demanda habitacional no Brasil, a política pública federal no setor de habitações e a relação com o mercado imobiliário.

\subsection{O MERCADO IMOBILIÁRIO E AS POLÍTICAS HABITACIONAIS}

Os fatores que englobam a produção e transformação do espaço geográfico estão associados, principalmente, com a busca e a necessidade por moradia. Questões sociais, econômicas, territoriais e políticas são determinantes para ocupação ordenada ou não da população nas cidades. Alguns fatores como crescimento demográfico, ocupação irregular do solo, falta de políticas públicas e de fiscalização, ocorrem em todas regiões do Brasil, e se acentuam em cidades maiores, como no Distrito Federal, onde se localiza o objeto de pesquisa.

A pressão populacional nos centros urbanos, a crise econômica, o desemprego e o alto custo do solo urbano associados à ausência de política habitacional, segundo a Caixa Econômica Federal (2011), foram alguns dos 
fatores que forçaram as famílias de menor renda a buscar por conta própria alternativas precárias de moradia. Este processo acelerou a favelização, a ocupação irregular da periferia e de áreas de risco, configurando, desta forma, os atuais problemas urbanos brasileiros.

A habitação, segundo Moreira (2013), possui várias características peculiares, dentre as quais pode-se destacar: necessidade básica; custo elevado; durabilidade; heterogeneidade; imobilidade; mercado reduzido em face do tamanho do estoque; custo de transações e mercado segmentado (os mercados habitacionais de baixa e alta renda apresentam características distintas). Assim, a necessidade por moradia fica associada ao mercado capitalista, pois as pessoas necessitam e consequentemente investem sua renda em imóvel, o que por sua vez move o mercado imobiliário. Por isso Moreira também afirma que a indústria da construção civil para fins habitacionais responde por parte significativa do Produto Interno Bruto (PIB) e da geração de emprego da economia.

Sobre a política habitacional a partir do Governo Federal de 2003 a 2010, Moreira (2013) explica que precisamente em 2003 inaugurou-se um novo período da política federal para a habitação. Segundo o autor, o período ainda em curso, com o Governo do período de 2011 a 2014, é marcado pela formulação de uma agenda política com temas sociais. A criação do Ministério das Cidades definiu a responsabilidade de elaborar, de maneira participativa e federativa, a Política Nacional de Desenvolvimento Urbano, o que inclui a nova política para o setor da habitação, em particular da Habitação de Interesse Social (HIS), como será explicitado posteriormente.

Segundo a Caixa Econômica Federal (2011) a situação começa a mudar a partir de 2003, com a criação do Ministério das Cidades e a aprovação da Política Nacional de Habitação (PNH) em 2004, assim as políticas habitacionais ganharam impulso no Brasil, que propôs uma visão ampliada e integrada das questões de desenvolvimento urbano das cidades. A CEF (2011) explica que a Política Nacional de Habitação é viabilizada por meio do Sistema Nacional de Habitação e também pelo Desenvolvimento Institucional, Sistema de Informação, Avaliação e Monitoramento, Plano Nacional da Habitação (PLANAB) e pela regulamentação do Estatuto das Cidades.

O Sistema Nacional de Habitação (SNH), articula ações integradas nos níveis federais, estaduais e municipais, e divide-se em dois sistemas: Sistema Nacional de Habitação de Interesse Social (SNHIS), voltado à população com renda entre 0 a 5 SM - salários mínimos e em Sistema de Habitação de Mercado (SHM), que atende, principalmente, às classes de renda entre 5 a 10 SM.

Os Programas do Sistema de Habitação de Interesse Social contemplam ações de urbanização de favelas, realocação de famílias em áreas de risco, 
alagados, cortiços, e outros. Já o Sistema de Habitação de Mercado atende à população com renda mais alta por meio de construtoras e incorporadoras que atuam como agentes promotores. Também pode atender a segmentos de baixa renda (mercado popular), desde que sem a contrapartida do poder público. Desse modo, segundo a Caixa (2011):

Cabe a Caixa a execução das ações do programa relativas a habitação, saneamento e infraestrutura urbana. Trata-se de um novo conceito de investimento em infraestrutura no Brasil que visa "romper barreiras e superar limites", por ser um indutor de transformações das cidades, que busca esgotar, com investimentos, o déficit de saneamento, da habitação e de urbanização nas favelas. Em 2009, foram contratados R \$ 41,8 bilhões dentro do Programa de Aceleração do Crescimento - PAC, dos quais 83,9\% foram direcionados a obras de habitação. (CAIXA, 2011).

Ainda de acordo com o estudo elaborado pela Caixa Econômica Federal (2011), em relação à crise financeira internacional de 2008, o Governo tomou várias medidas para manter o ritmo do crescimento econômico do País, estimulando o setor da construção civil e neste contexto foi concebido o Programa "Minha Casa, Minha Vida" (PMCMV) operado pela CEF, que segundo a própria instituição, representa um marco na política de acesso à moradia, articulando ações do Governo Federal em parceria com os Estados, Municípios e iniciativa privada.

Especificadamente, segundo Moreira (2013), quanto ao Programa Minha Casa, Minha Vida pode-se dizer que ele consiste em uma ação de cunho habitacional, lançado pelo Governo Federal em março de 2009 (Medida Provisória $n^{\circ} 459 / 2009$, de março de 2009, convertida na Lei $n^{\circ} 11.977$, de 07 de julho de 2009), cuja meta era realizar a construção de um milhão de moradias, sanando cerca de $15,0 \%$ do déficit habitacional do país.

As metas do programa são audaciosas, e segundo a Caixa Econômica Federal (2012), o programa federal "Minha Casa, Minha Vida" tem como objetivos:

a) Redução significativa do déficit habitacional crônico brasileiro;

b) Favorecimento da regularização fundiária urbana;

c) Criação de fonte de demanda de capital e trabalho como medida anticíclica frente aos impactos sofridos pelo país devido à crise mundial de 2008;

d) Aumento do investimento na construção civil. 
O programa de grandes dimensões gerou por parte do governo esforços que estão sendo geridos pelo Ministério das Cidades e a operacionalização é feita pela Caixa Econômica Federal. Moreira (2013) explica que o programa incorpora a aquisição de terreno e construção ou requalificação de imóveis contratados como empreendimentos habitacionais em regime de condomínios ou loteamento, constituídos de apartamentos ou casas, que depois de concluídos, são alienados às famílias de baixa renda espalhadas por todo país. A execução das obras dos empreendimentos é realizada por construtoras devidamente habilitadas e contratadas pela Caixa Econômica Federal, e estas que se responsabilizam pela entrega dos imóveis dentro dos prazos estipulados, prontos para moradia e legalizados.

Os investimentos do Governo Federal na segunda etapa do programa habitacional Minha Casa, Minha Vida (MCMV2) são quase nove vezes maiores que o programa original, lançado em março de 2009. Segundo Moreira (2013), no MCMV2, o Governo está investindo R\$ 278,2 bilhões de 2011 a 2014, contra R\$ 34 bilhões da primeira versão do Programa. O PMCMV promove a construção de novas unidades habitacionais voltadas às camadas da população com menor renda, concedendo subsídios, principalmente para a faixa de renda de 0 a 3 salários mínimos.

De acordo com Moreira (2013), na segunda fase, o PMCMV pretende construir dois milhões de moradias até 2014. A faixa de renda das famílias beneficiadas também foi reduzida, pois na primeira versão do projeto, o objetivo era atender famílias com rendimentos de até $\mathrm{R} \$ 1.530,00$ mensais, enquanto agora o Governo irá priorizar $60 \%$ das casas para famílias com renda de até R\$ 1.395,00 mensais. O Quadro 1 aponta dados do programa habitacional no Distrito Federal, diferenciando a Região Administrativa do empreendimento, a faixa salarial familiar, a situação das obras e os preços dos imóveis. 
Quadro 1 - Preços dos imóveis e renda necessária para aquisição de imóveis pelo Programa Habitacional Morar Bem do Distrito Federal (2013)

\begin{tabular}{|c|c|c|c|}
\hline $\begin{array}{l}\text { EMPREENDIMENTO NAS } \\
\text { REGIÕES ADMINISTRATIVAS }\end{array}$ & $\begin{array}{l}\text { FAIXA SALARIAL } \\
\text { FAMILIAR MENSAL }\end{array}$ & SITUAC̣ÃO ATUAL & PREÇO \\
\hline PARANOÁ - PARANOÁ PARQUE & DE 0 A R $\$ 1.600,00$ & OBRA Já INICIADA & $\mathrm{R} \$ 65.000,00$ - APART DE $2 Q$ \\
\hline RECANTO DAS EMAS & DE 0 A R $\$ 1.600,00$ & LIIITAC̦ÃO CONCLUÍDA & $\operatorname{R} \$ 58.316,53$ - APART DE $2 Q$ \\
\hline RIACHO FUNDO II (3 ETAPA) & DE 0 A R $\$ 1.600,00$ & LIIITAC̦ÃO CONCLUÍDA & $\operatorname{R} \$ 63.503,31$ - APART DE $2 Q$ \\
\hline $\begin{array}{l}\text { RIACHO FUNDO } \|- \\
\text { PARQUE DO RIACHO }\end{array}$ & DE R\$ 1.600,00 A R\$ $3.275,00$ & OBRA JÁ INICIADA & $\begin{array}{l}\mathrm{R} \$ 74.985,00 \text { - APART.DE } 2 \mathrm{Q} \\
\mathrm{R} \$ 84.983,00 \text { - APART. DE } 3 \mathrm{Q}\end{array}$ \\
\hline SANTA MARIA & DE R\$ 1.600,00 A R\$ 8.136,00 & OBRA Já INICIADA & $\operatorname{R} \$ 96.451,73$ - APART. DE $2 Q$ \\
\hline $\begin{array}{c}\text { SÃO SEBASTIÃO - JARDINS } \\
\text { MANGUEIRAL }\end{array}$ & DE R\$ 2.488,00 A R\$ 8.136,00 & EM OBRAS & $\begin{array}{l}\mathrm{R} S 131.016,17 \text { - CASA DE } 2 Q \\
\mathrm{R} \$ 156.651,88 \text { - CASA DE } 3 Q \\
\mathrm{R} \$ 116.065,41 \text { - APART DE } 2 Q\end{array}$ \\
\hline GAMA & DE R\$ 1.600,00 A R\$ 8.136,00 & LICITAC̦ÃO CONCLUÍDA & $\begin{array}{l}\mathrm{R} \$ 111.746,42 \text { - APART DE } 2 Q \\
\mathrm{R} S 138.218,02 \text { - APART DE } 3 Q\end{array}$ \\
\hline SAMAMBAIA & DE R\$ 1.600,00 A R\$ 8.136,00 & OBRA JÁ INICIADA & $\begin{array}{l}\mathrm{R} \$ 107.450,00 \text { - APART DE } 2 Q \\
\mathrm{R} \$ 133.300,00 \text { - APART DE } 3 Q\end{array}$ \\
\hline SOBRADINHO & DE R\$ 1.600,00 A R\$ 8.136,00 & LICITAC̦ÃO CONCLUÍDA & RS $116.000,00$ - APART DE $2 Q$ \\
\hline ITAPOÃ - ITAPOÃ PARQUE & DE R\$ O A R $\$ 3.275,00$ & LICITAC̦ÃO CONCLUÍDA & $\begin{array}{l}\text { RS } 76.000,00 \text { - APART D } 2 \text { Q } \\
\text { RS 83.219,00 - APART DE } 3 \text { Q }\end{array}$ \\
\hline PLANALIINA - MESTRE D'ARMAS & DE 0 A R $\$ 1.600,00$ & EDITAL EM ELABORAC̦ÃO & R\$ 76.000,00 - APART DE 2 Q \\
\hline $\begin{array}{l}\text { RECANTO DAS EMAS- } \\
\text { VARGEM DA BENÇ̃̃OO }\end{array}$ & DE 0 A R $\$ 3.275,00$ & LIIITAÇÃO CONCLUÍDA & $\begin{array}{l}\text { RS } 75.992,40 \text { - APART DE } 2 Q \\
\text { R\$ 83.065,76 - APART DE } 3 Q\end{array}$ \\
\hline
\end{tabular}

Fonte:www.morarbem.df.gov.br (2013) Org.: Nunes, L. M. dos S. (2014)

Observa-se pelo Quadro 1 que em todas Regiões Administrativas contempladas pelo Programa Habitacional Morar Bem, do Governo do Distrito Federal, as unidades habitacionais ofertadas são em apartamentos. A única região que dispõe de apartamentos e casas é em São Sebastião, no Jardins Mangueiral. Também a renda mensal bruta familiar exigida é maior do que para aquisição do imóvel em qualquer outra Região Administrativa. Ressalta- 
se que as qualidades do empreendimento são melhores no que se refere ao planejamento, à infraestrutura paisagística do Bairro, áreas para prática de lazer e cultura, espaços para futuras instalações de equipamentos de serviços também se destacam.

A produção de imóveis residenciais hoje impulsiona a economia e proporciona oportunidades de desenvolvimento para o país. As obras geram milhares de empregos e representam uma significativa contribuição para o aquecimento da economia. Apesar da segregação residencial promovida pelas faixas de renda, há como exemplo o bairro Jardins Mangueiral, que desde o início das obras empregaram uma quantidade significativa de trabalhadores que são moradores da Região Administrativa de São Sebastião, gerando efeitos benéficos para população local.

Dentre as várias medidas que podem impulsionar a expansão econômica de um país, o financiamento imobiliário tem um papel de destaque, segundo Moreira (2013). Ele explica que os volumes de recursos direcionados a essa modalidade de crédito impulsionam a indústria da construção civil, que por sua vez, é formada por uma cadeia produtiva a montante e a jusante geradora de produção, emprego e renda.

As transformações socioeconômicas ocorridas na sociedade interferem diretamente na quantidade e na qualidade das habitações necessárias para atender os anseios da população brasileira. Nas últimas décadas, o Brasil tem apresentado grandes transformações no aspecto habitacional. De acordo com o estudo da CEF (2011), três fatores se destacam como causas dessas mudanças: a emigração da área rural para as cidades, o envelhecimento da população e modificações nas configurações familiares. Estes fatores foram determinantes para a urbanização acelerada e desordenada das cidades.

Hoje existe uma grande concentração de domicílios nas grandes metrópoles, locais onde os trabalhadores buscam melhores condições de vida associando mais acesso aos empregos e melhores condições de moradia. Mas o processo de urbanização no Brasil e especificamente no DF, local da pesquisa, pressiona a expansão das grandes metrópoles em direção à periferia.

Nesse processo de urbanização e necessidade por moradia, o conceito de habitação apropriada, digna, segura e confortável pode ser diferenciado em cada região. Porém, considera-se universal o desejo de uma família ou indivíduo possuir um imóvel próprio. Esta busca pela habitação molda o mercado de acordo com as especificidades locais.

O bem habitação conforme o estudo da CEF (2011) pode ser compreendido como unidade residencial e possui características particulares que fazem com que a dinâmica do mercado habitacional seja bastante distinta em relação a 
maioria dos demais mercados. O estoque de residências é bastante heterogêneo. Mesmo considerando-se apenas uma única tipologia, não existe no mercado um imóvel exatamente igual ao outro. A heterogeneidade do "bem habitação" atribui a cada unidade habitacional um preço diferente, que depende das características de localização no espaço urbano e também da sua singularidade, observada em relação às características espaciais e estruturais.

Sobre esse fato apontado, pode-se associar que os imóveis urbano, agregam valores ou são desvalorizados relacionando, por exemplo, com a distância do imóvel e deste em relação ao centro da cidade, a proximidade com veículos de transporte público, a proximidade com o comércio local, com a avenida principal da cidade, com os equipamentos públicos, enfim da localização do imóvel. Interfere na valorização as características e a qualidade dos materiais utilizados na construção, a mão-de-obra, a estrutura física da obra. No caso de prédios, há a diferenciação dos valores conforme o andar onde é o imóvel, quanto mais alto, mais elevado preço do imóvel. Enfim, diversos fatores influenciam nos valores diferenciados para os imóveis.

Outro fator que diferencia os valores dos imóveis são os tipos de moradias, no bairro Jardins Mangueiral há prédios, todos com apartamentos de 2 quartos, e casas, que por sua vez se dividem em casas de 2 quartos e casas de 3 quartos. Cada tipo de imóvel tem preços diferenciados. Além das diferenças dos valores induzidos pelas características físicas do imóvel, o valor pago pelo comprador varia de acordo com a renda familiar, pois como o programa habitacional faz parte do Programa Minha Casa, Minha Vida, a renda familiar é que determina se a compra terá subsídio do Governo e a porcentagem a ser adquirida no subsídio ou se a compra será apenas com recursos próprios.

Segundo informações da CEF (2011), desde que sejam fornecidas condições compatíveis com o perfil socioeconômico, as unidades residenciais geralmente são produzidas pela iniciativa privada de forma independente, mas principalmente, associada a programas de governo. $\mathrm{O}$ custo elevado da produção, aliado ao alto preço da terra urbana dificulta a conquista de um domicílio digno e seguro para a população de menor renda. Desta forma as políticas públicas habitacionais são fundamentais para facilitar o acesso à moradia. Assim, é importante um aprofundamento conceitual que represente a configuração econômico-social e espacial da carência habitacional no Brasil.

Segundo Garcia e Castelo (2006) o déficit habitacional se refere às carências habitacionais de uma determinada sociedade não restritas à falta de moradias, inclui também as más condições das unidades habitacionais existentes. O déficit habitacional é uma fotografia que mostra o excesso de população que necessita de habitações. Ou seja, é o excedente entre a demanda e oferta de um bem de caráter social. 
A Fundação João Pinheiro produziu o estudo mais difundido no Brasil a respeito do tema que foi adotado pelo Ministério das Cidades na formulação da Política Habitacional. Este conceitua o déficit habitacional como as deficiências do estoque de moradias. Considerando neste cálculo as moradias em estado precário que precisam ser repostas e as novas que representam um incremento do estoque, em função da coabitação familiar ou da moradia em locais inadequados. Assim o déficit habitacional pode ser compreendido como déficit por reposição e incremento de estoque.

Esse estudo mais recente no Brasil, realizado pela Fundação João Pinheiro, em parceria com a Secretaria Nacional de Habitação do Ministério das Cidades, em 2008, e publicado em abril de 2011 teve como base de dados, a Pesquisa Nacional por Amostra de Domicílios (PNAD), divulgada pela Fundação Instituto Brasileiro de Geografia e Estatística (IBGE) no segundo semestre de 2009. E segundo o estudo (Fundação João Pinheiro, 2011) em 2008, o déficit habitacional estimado correspondia a 5.546 milhões de domicílios, dos quais 4.629 milhões, equivalentes à $83,5 \%$, estavam localizados nas áreas urbanas.

$\mathrm{O}$ estudo também analisa o déficit habitacional segundo faixas de renda média familiar mensal, em termos de salários mínimos. De acordo com Moreira (2013) resultado mostrou que a maior concentração do déficit habitacional se dava na faixa até três salários mínimos $(89,6 \%)$. A categoria "mais de três a cinco" compreendia $7,0 \%$ das famílias, a mais de cinco a 10 " era $2,8 \%$ e a "mais de 10 " somavam $0,6 \%$. Assim, as famílias com renda até cinco salários mínimos totalizavam $96,6 \%$ do déficit habitacional urbano.

É importante destacar no estudo sobre as políticas habitacionais a questão do valor da renda mensal familiar. Moreira (2013) explica que quanto ao entendimento de qual é a despesa da União com o Programa Minha Casa, Minha Vida, é importante observar que a maior parte das moradias é destinada a famílias da área urbana com renda mensal de até $\mathrm{R} \$ 1,6$ mil e para famílias na área rural com renda anual de até $\mathrm{R} \$ 15$ mil reais. Elas comprarão as residências por um preço muito inferior ao seu custo, ou seja, receberão um grande subsídio.

O Programa arca com um determinado valor do imóvel, e o restante é financiado, com prestações que variam de acordo com a renda salarial da família contemplada e com o valor da entrada paga no início da compra. Para tanto, o Programa é caracterizado como um programa de transferência de renda.

O Programa é executado por meio do Fundo de Arrendamento Residencial (FAR) e do Fundo de Desenvolvimento Social (FDS). Moreira (2013) explica que em decorrência da Medida Provisória n 561, de março de 2012, a União passou a integralizar cotas do FAR. Até então, apenas transferia os recursos 
para o FAR, que eram contabilizados como gastos de custeio. Por causa da mudança feita pela MP 561/2012, os recursos orçamentários destinados a cobrir os subsídios do Programa passaram a ser contabilizados como inversões financeiras, ou seja, como investimentos. A respeito nota-se que:

O Programa Minha Casa, Minha Vida significou novo aporte de recursos para a habitação. Concebido como uma política anticíclica, que visou a robustez à economia brasileira em face da crise financeira internacional que eclodiu em 2008, o Programa direcionou R\$ 34 bilhões em subsídios à produção habitacional de um milhão de habitações. Dessa forma, entre 2003 e 2009, o volume de investimentos no setor habitacional foi ampliado em aproximadamente $600 \%$, saindo do patamar de R \$ 5,7 bilhões para cerca de R\$ 69,2 bilhões em 2009 (FIX; Arantes, 2009).

No estudo adotado pela CEF (2011), e que dá subsídio para compreensão do processo de planejamento, construção e financiamento dos imóveis no Jardins Mangueiral, o conceito adotado foi de demanda habitacional que representa a necessidade dos indivíduos residirem em local adequado, sob o aspecto demográfico das relações sociais e econômicas da população com o meio urbano.

Logo, de acordo com a conceituação estabelecida, a demanda habitacional total é relacionada ao perfil demográfico e socioeconômico da população, bem como a sua localização no sítio urbano. Sua distribuição no território é definida pelas características da tipologia predominante de moradias (casas ou apartamentos), da configuração espacial da malha urbana e outras características topológicas.

Para a Caixa Econômica Federal (2011), a análise histórica demonstra que a atual Política Nacional de Habitação, instituída pelo Governo Federal em 2004, constitui um marco para o setor habitacional por abordar a questão da moradia de maneira ampla e integrada aos serviços urbanos e afirma que o enfrentamento da carência de moradias exige um esforço integrado do Governo e da iniciativa privada. E aqui acrescenta-se que não basta ter direito e acesso à moradia. Morar em um bairro exige também a necessidade de equipamentos públicos que atendam às necessidades dos moradores.

Observa-se que o histórico das políticas nacionais para habitação mostra como os programas tornaram o problema habitacional uma obrigação do Estado e um direito do cidadão, na interpretação de Moreira (2013), uma questão de mercado, repassando para o setor privado o protagonismo na produção 
de habitações a serem financiadas. Esse modelo, que se baseia na lógica de mercado, e fez com que as unidades residenciais produzidas fossem tidas como mercadorias, portanto gerando renda para seus proponentes, o que de certa forma explica o fato de as políticas sempre terem atingido, predominantemente, a classe média e terem atendido aos interesses do empresariado da construção civil.

Como bem retratado no bairro Jardins Mangueiral, que foi destinado para população de classe média do Distrito Federal, onde por ser originário de todo um contexto de planejamento urbano, beneficia os moradores mas principalmente às construtoras envolvidas na construção e manutenção do bairro. Sobre a relação entre política habitacional e mercado imobiliário, Moreira (2013) descreve que:

Essa distorção da política habitacional revela a incompatibilidade da finalidade social da política habitacional com o modo empresarial de produção de moradia. $\mathrm{Na}$ impossibilidade de conciliação, os interesses dos empresários influenciam e até certo ponto determinam os investimentos públicos para habitação e o público para o qual eles seriam direcionados, em detrimento da função social da política habitacional. (MOREIRA, 2013, p.30).

O Estado somente não deve prover a oferta de habitações, contudo deve criar mecanismos de facilitem a compra e o pagamento pelos imóveis, associando ao planejamento urbano, que pode proporcionar lugares de moradia com infraestrutura básica, associando com leis que fiscalizem e inibam a ocupação irregular do solo. Os valores dos imóveis podem ser mais baixos, caso não seja visado somente o lucro por parte das construtoras.

Pode-se compreender que os critérios socioeconômicos se relacionam para a ocupação e transformação do espaço urbano e a questão que interliga o mercado imobiliário com o Programa "Minha Casa, Minha Vida”. Evidenciando portanto valores de imóveis diferenciados seguindo três critérios: a) renda média mensal familiar; b) tamanho dos imóveis e c) localização da cidade com relação a sua proximidade com o núcleo central da cidade. Acrescenta-se que, de fato as atuais políticas habitacionais beneficiaram famílias de baixa renda, o que, no entanto, pode ser constatado é a diferenciação dos espaços onde são construídas as residências para as famílias de acordo com a renda salarial. Os conjuntos habitacionais são construídos com características próprias ao espaço das cidades e as condições socioeconômicas dos compradores e habitantes.

No Distrito Federal não se difere os aspectos que dialeticamente se 
misturam, trazendo soluções para alguns problemas, como aumento na oferta de moradias, mas trazendo também todos problemas urbanos tipicamente vividos nas grandes cidades. Sobre Brasília e as tendências metropolitanas, Neto (2006) afirma:

[...] é possível observar um espraiamento das manchas metropolitanas brasileiras em direção a espaços periféricos (ou peri-urbanos) nas suas formas espaciais; incorpora (áreas, regiões, zonas, bairros) a dinâmica da moderna economia, e reproduz o capital imobiliário, à medida que (re)valoriza espaços, "escolhidos" pelo capital [...] (NETO, 2006, p. 114).

$\mathrm{Na}$ produção do espaço urbano, ao construir uma área residencial para determinada classe social, o investimento em novas lojas, redes de hipermercados, escritórios e demais serviços privados são inseridos na lógica do capital. Santos (2003) afirma:

[...] os lugares escolhidos acolhem e beneficiam os vetores da racionalidade dominante mas também permitem a emergência de outras formas de vida [...] Com a globalização, todo e qualquer pedaço da superfície da Terra se torna funcional às necessidades, usos e apetites de Estados e empresas nesta fase da história. (SANTOS, 2003, p. 80-81).

No entanto, a análise realizada sobre a transformação do espaço teve significativa importância para se compreender os processos pelos quais a cidade de São Sebastião (DF) tem vivido. Sobre o espaço geográfico, Santos (2003) afirma:

Um conceito básico é que o espaço constitui uma realidade objetiva, um produto social em permanente processo de transformação. O espaço impõe sua própria realidade; por isso a sociedade não pode operar fora dele. Consequentemente, para estudar o espaço, cumpre apreender sua relação com a sociedade, pois é esta que dita a compreensão dos efeitos dos processos (tempo e mudança) e especifica as noções de forma, função e estrutura, elementos fundamentais para a nossa compreensão da produção de espaço. (SANTOS, 2003, p. 67). 
As políticas habitacionais representam uma importante ferramenta para organizar a forma de ocupação do espaço urbano e atender as necessidades referentes ao setor de moradia, e sob essa ótica, a renda média bruta familiar é o que define como se dará a inserção do indivíduo e sua família nos programas habitacionais. Quanto maior a renda, maior o poder aquisitivo, melhor será o lugar da cidade onde poderá ser comprado o imóvel, que por sua vez, são imóveis localizados em setores com melhor infraestrutura. 


\section{REFERÊNCIAS}

BONDUKI, Nabil. Origens da Habitação Social no Brasil. São Paulo: Estação Liberdade/FAPESP, 1998.

BORGES, Joamara Mota. Políticas habitacionais, condições de moradia, identidade e subjetividade no Programa Minha Casa, Minha Vida em Águas Lindas de Goiás. 2013. 133 f. Dissertação (Mestrado em Geografia), UNB, Braślia, 2013.

BRASIL. Ministério do Planejamento. PAC2. Minha Casa Minha Vida. Disponível em: <www.pac.gov.br/minha-casaminha-vida> Acesso em: 05/10/2014

BRASIL. Déficit Habitacional no Brasil 2007. Ministério das Cidades. Secretaria Nacional de Habitação. Brasilia, 2009.

BRASILLIA. Programa Morar Bem. Disponível em: http://www.morarbem.df.gov.br/direito.aspx? pagina=direito. Acesso em: 08 set. 2014.

CAIXA. Demanda habitacional no Brasil. Caixa Econômica Federal. Braślia, 2011.

COMPANHIA DE PLANEJAMENTO DO DISTRITO FEDERAL - CODEPLAN. Pesquisa Distrital por Amostra de Domićlios - PDAD - 2013 São Sebastĩ̃o. Braślia (DF), 2013.

FERREIRA, Aurélio Buarque de Holanda. Miniaurélio Século XXI Escolar: 0 minidicionário da língua portuguesa.4. ed. rev. Ampliada. Rio de Janeiro: Nova Fronteira, 2000.

GOVERNO DO DISTRITO FEDERAL - GDF. Instituto de Planejamento Territorial e Urbano - IPDF. Plano Diretor de Ordenamento Territorial do Distrito Federal. Projeto de Lei Complementar. Brasilia, 1996.

JARDINS MANGUEIRAL. Sobre o Projeto Jardins Mangueiral. Disponível em: <http://www.jardinsmangueiral. com.br/>. Acesso em 27 mai. 2014.

MOREIRA, Edison Marques. Política econômica: Um olhar sobre a atual situação política habitacional no Brasil. Indic. Econ. FEE, Porto Alegre, v.40, n. 3, p. 21-32, 2013.

NETO, J. M. R.; Menon, F. G. da S.; Nóbrega, M. das D. S.; LMA, S. F. C de. Brasília e seu entorno: consideraç̃oes sobre os desafios de metrópole emergente. Revista Múliipla, Brasília, 10(20): 103-117, junho - 2006. Disponível em: < file://C:/Users/luciana/Downloads/multipla20-ibre.pdfs Acesso em: 13/09/2014.

SANTOS, Milton. A Natureza do Espaço: Técnica e Tempo, Razão e Emoção. SãoPaulo: Editora da Universidade de São Paulo, 2002. (p.233-259)

SANTOS, Milton. Metamorfoses do Espaço Habitado: Fundamentos Teóricos e Metodológicos da Geografia. 6 ed. São Paulo: Editora da Universidade de São Paulo, 2012. (p.41-49) 
Seminário de Pesquisa, Pós-Graduacãoo e Inovação da Regional Catalão 